\title{
Research into development of the psychological capital structure of the enterprise technological innovation team
}

\author{
Yueping $\mathrm{Du}^{1}$, Jiangyue $\mathrm{Qu}^{1, \mathrm{a}}$ \\ ${ }^{1}$ School of Economics and Management, Xidian University, Xi' an 710126, China \\ aqujiangyue2014@126.com
}

Keywords: Enterprise technological innovation team; psychological capital; structure; development Abstract. Achievements of the enterprise technological innovation team can reflect the team' $s$ psychological capital. Thus, this paper introduces the team's psychological capital and its formation, and analyzes constituents and content of the psychological capital structure of the enterprise technological innovation team. Based on the above introduction and analysis, plans and approaches to develop the team' s psychological capital structure are discussed at an attempt to provide references for people interested in the topic.

\section{Introduction}

To build a reasonable psychological capital structure for a team can improve the team's efficiency. With the increase of scientific research complexity and investment intensity, enterprises need to enhance efficiency development of their technological innovation team so as to achieve better performance. Some scholars have studied the issue of psychological capital structure development for the enterprise technological innovation team, aiming at seeking feasible approaches to improve their innovation performance.

\section{Team's psychological capital and its formation}

Team's psychological capital refers to the positive mental power for the development of a team. As a shared positive mental state of teammates formed through coordination and interaction, it can reflect the consistency level of individuals' psychological cost. Since market competition has become increasingly fierce, enterprises have started paying attention to their team's positive psychological energy. Increase of the team' s psychological capital can obviously better display the team's functions, thus achieving remarkable performance. According to the forming process of the team's psychological capital, teammates achieve a consistent cognition of their team during the mutual communication process. The process is, in essence, a process of emotional appeal and behavioral appeal. Affected by the emotional and behavioral appeal, teammates will show similar emotions and behaviors, which, in turn, can enhance the whole team, and lead to realization of a consistent cognition among teammates.

\section{Analysis of the psychological capital structure of the enterprise technological innovation team}

After the formation of the team's psychological capital, a certain capital structure will come into being after continuous accumulation. Different teams have different psychological capital structures and can bring different values to enterprises.

A Analysis of constituents of the psychological capital structure of the enterprise technological innovation team

While developing the psychological capital structure of the technological innovation team, enterprises can divide individual psychological capital into congenital factors and acquired factors, and regard individual psychological capital as measurable and developable psychological traits which can demonstrate the team's innovation performance. According to the idea, stable and congenital psychological traits are divided into emotions, values, cognition and motivation; while flexible and acquired psychological traits are divided into optimism attribution, hope, sense of 
efficacy and persistence. As a tacit agreement among individual psychological interaction, the team's psychological capital is the intensive capital reflecting positive mental power of teammates, and can fully display integrated advantages of the whole team. Therefore, the team's psychological capital is a collection of psychological traits which can improve the team's creativity. Not only can it demonstrate the individual psychological traits, but also it can show the conformity and particularity of the team's psychology [1]. According to characteristics of the team's psychological, the psychological capital of the enterprise technological innovation team can be divided into implicit psychological capital and explicit psychological capital.

B Analysis of the structure content

By analyzing the content of the psychological capital structure of the enterprise technological innovation team, it can be found that the explicit psychological capital can make use of four positive psychological statuses - team efficacy, persistence, shared vision and optimism attribution-to demonstrate its developmental and flexible characteristics. Amon them, the team efficacy can form a shared belief of reaching certain level. The team can make use of the ability to take some actions and make some achievements. As to persistence, it is the ability of a team to quickly recover from fatigue and failures. Optimism attribution is a psychological status of a team to attribute positive effects to positive changes, experiences and demands of their team. In terms of shared vision, it is the common pursuit of all teammates, which can better integrate all teammates into the team. The implicit psychological capital refers to developmental and stable psychological traits, including cognitive advantages, emotional intelligence, trait motivation and values. Among them, cognitive advantages refer to cognitive achievements accumulated by a team, which reflects the team's professional knowledge and problem-solving ability. Emotional intelligence means that creativity of teammates is achieved through their positive emotions, and it reflects the emotional experience of a team [2]. Trait motivation refers to steadiness of a team to pursue a certain goal. Values are the basis for a team to realize its value objectives.

\section{Development of the psychological capital structure of the enterprise technological innovation team}

\subsection{Development plan}

During the development process of the psychological capital structure of the enterprise technological innovation team, enterprises can formulate corresponding strategies based on the following periods. In the first period, enterprises should obtain intangible psychological capital for a team so that positive psychological elements of the team can be well developed. In the second period, enterprises need to cultivate the team's harmonious psychological state so that the team's psychological capital can be further developed. In the third period, enterprises should give full play to the collaborative advantages of the team's positive mental power [3]. In the last period, the team's performance can be improved through enhancement of cooperation, trust and efficacy within a team.

A Development approaches

1 Approaches to obtaining intangible psychological capital

In order to obtain intangible psychological capital, positive individual psychological capital elements should first be fully developed. To the end, first, enterprises should help teammates formulate challenging work objectives for teammates so as to fully stimulate their work motivation. Then, enterprises need to guide teammates to analyze approaches to realize their work objectives. In this way, teammates can find more approaches to materialize their objectives and alleviate their psychological burden. Second, enterprises should enhance cultivating teammates' optimism so that they can be more tolerant to the past, more grateful of the present and more cheerful about the future. Third, enterprises should provide experiences which can give teammates a sense of achievement, and increase their self-efficacy by allowing them to share successes of the team [4]. Last but not least, enterprises should strengthen teammates' ability to cope with adverse situations and make use of surrounding resources to finally increase their persistence.

2 Approaches to cultivating the team's harmonious psychological status 
After preliminary exploration of the team's psychological cost, it is necessary to create a favorable teamwork atmosphere so that a harmonious psychological status can be formed. To the end, first, enterprises should enhance education of teammates' psychological health so that teammates can maintain a positive psychological status. Besides, enterprises need to build psychological health archives of teammates, and give psychological counselling to individuals so as to achieve dynamic management of members' psychological status. Second, in order to achieve both internal and external harmony, enterprises need to improve the working environment. Favorable environmental conditions can fully display functions of psychological capital. Some environmental cultural factors can stimulate teammates' emotional synesthesia and maintain the team's passion for creativity. Last but not least, the team's cultural construction should be enhanced. To be specific, an internal information interaction and communication mechanism within the team should be built so that teammates can keep an open psychological status and take the initiative to improve their own psychological capital.

3 Approaches to displaying coordinated advantages of the team's mental power

In order to fully display coordinated advantages of the team's mental power, enterprises need to conduct an overall development of the team's psychological capital. To the end, first, enterprises should build a shared vision for the team so as to increase the team's self-efficacy. As we know, Teammate A has the innovational thinking ability; Teammate B has the ability to organize production; Teammate $\mathrm{C}$ has the ability of coordinating; and Teammate $\mathrm{D}$ has the ability of monitoring and control. Through mutual interaction, these teammates can integrate respective advantages to form a shared cognition. Based on that, teammates will be confident about the shared vision, and actively explore approaches to realizing the shared vision. Second, a specialized internal learning platform should be put place so as to increase mutual trust within the team. Third, in order to enhance teamwork, a series of theme training activities can be held so that teammates can maintain a positive teamwork status [5]. Last but not least, difficult scenarios should be designed so as to enhance persistence of teammates, and enterprises should also give a hand to teammates to formulate relevant plans. In this way, the team will be more adaptable to different situations.

\section{Conclusions}

All in all, psychological capital is the intangible asset for an enterprise's production and operation activities. Under the condition of limited assets, acceleration of psychological capital development can bring more benefits for an enterprise. Development of the psychological capital structure of the enterprise's technological innovation team can create a team with strong creativity and innovation ability for an enterprise. With such a team, the enterprise will achieve better development.

\section{References}

[1]ZHANG Xiaoyan. Development strategy of scientific and technological innovation team in enterprises based on psychological capital[J]. Journal of China University of Mining \& Technology (Social Sciences), 2011, 03: 85-89.

[2]ZHANG Ming, GU Zhuguang \& TAN Jiangtao. Development of entrepreneurs' psychological capital based on the E-PCI-S model[J]. China Industrial Economies, 2012, 12: 102-114.

[3]ZHANG Hongli \& HU Chenglin. The research of construction and development of entrepreneurial team based on psychological capital theory[J]. Finance \& Economics of Xinjiang, 2014, 06: 21-28.

[4]ZHANG Ming \& HU Zhuguang. The research of psychological capital effects in management: Retrospect and prospect[J]. Journal of Business Economics, 2015, 04: 32-42.

[5]XIANG Gaoyue, SHEN Gusu \& SHEN Yongjian. Research into the formation mechanism and relevant development of the team psychological capital[J]. Leadership Science, 2016, 08: 45-48. 